\title{
Factors Predicting the Physical Activity Behavior based on Theory of Reasoned Action among Chronic Low Back Pain of the Patients Referring to Comprehensive Health Service Centers in the Shahid Beheshti University of Medical Sciences in Tehran, Iran.
}

Short running: Physical Activity behavior of Chronic Low Back Pain prediction

\begin{abstract}
Mohammad Hossein Delshad ${ }^{1}$, Alireza Hidarnia ${ }^{2}$, Fatemeh Pourhaji ${ }^{3}$
1. Postdoctoral Fellow/ Assistant Research of Health Education and Health Promotion Department, Faculty of Medical Sciences, Tarbiat Modares University, Tehran, Iran. (H.Delshad@modares.ac.ir)

2. Professor of Health Education and Health Promotion Department, Faculty of Medical Sciences, Tarbiat Modares University,Tehran,Iran.( hidarnia@modares.ac.ir)

3. Postdoctoral Fellow / Assistant Research of Health Education and Health Promotion Department, Faculty of Medical Sciences, Tarbiat Modares University, Tehran, Iran.
\end{abstract} (Fatemeh.pourhaji@modares.ac.ir)

Corresponding author:

* Alireza Hidarnia

Department of Health Education and Health Promotion, Faculty of Medical Sciences, Tarbiat Modares University, Tehran, Iran.

No 215, Department of Health Education and Health Promotion, Faculty of Medical Sciences, Tarbiat Modares University, Ghisa st., Jalae Ale Ahmd Ave , Tehran, Iran .

P.O. BOX: $14115-111$

Tel:+98 (21) 82883817

Fax: $+98(21) 82883817$

E-mail:Hidarnia@modares.ac.ir

All authors stated that there is no conflict of interest for this manuscript 
Abstract

Background: Low-level physical activity (PA) among Chronic Low Back Pain (cLBP) is associated with various biopsychosocial factors, and PA is effective in the domains of quality of life (QoL).

Objectives: This research aimed to study the predictors of physical activity behavior among cLBP patients referred to comprehensive health service centers in the Shahid Beheshti University of Medical Sciences (SBUMS) in Tehran, Iran.

Methods: In the present study 280 eligible patients with cLBP who referred to comprehensive health service centers in the SBUMS in Tehran, Iran from 13 January to 11 March 2019 were random selected. To diagnose the predictors of PA behavior, all the Theory of Reasoned Action (TRA) constructs were examined as risk factors to see if they influence on the probability of PA behavior occurrence and were interpreted through odds ratio (OR). SPSS version 21 was used to analyze the data.

Results: Totally 280 cLBP patients with mean age of $57.07 \pm 13.09$ years old participated in the study. This study showed that intention was significant predictor for perform the PA behavior OR (\%95Cl): 1.431(1.148-1.714), $p$-value <0.001), behavior beliefs could predictor for attitude OR (\%95Cl): 1.276(1.112-1.427), $p$-value $=<0.001)$. attitude, normative beliefs, subjective norm , and evaluation outcome behavior could predictors the CLBP patients for intention to perform the PA behavior OR (\%95CI): 1.189(1.033-1.367), p-value=0.016)., OR (\%95Cl): 1.158(1.08-2.208), p-value<0.001) ., OR (\%95CI):1.104(1.08-1.128), p-value=0.003) ., OR (\%95CI): 0.814(0.74-1.554), p-value<0.001), but motivation to comply could predict the cLBP patients for subjective norm OR (\%95Cl): $1.077(0.891$ 1.263), p-value=0.093).

Conclusion: This study showed that the CLBP patients who were normative beliefs and evaluation regarding PA behavior could effect on the intention to engage in greater PA than those with other constructs.

Key words: Exercise, Health Behavior, Attitudes, Referral, Quality of Life, Low Back Pain, Health Services, Models, Outcome Assessment (Health Care).

Trial registration: TCTR20190728001, registered in 2019.07.28 


\section{Introduction}

A lot of the population suffers from Chronic Low Back Pain (cLBP). cLBP is a costly and prevalent condition could want to physical disabilities, social and mental health engagement ${ }^{1}$, cLBP is determined through a complicated interaction among pain, behavior and biopsychosocial factors ${ }^{2}$.

Although, there are several treatment procedures to improve cLBP, cLBP control and management programs to be more effective than others support to change behavior ${ }^{2}$. Physical Activity (PA) is observed as an effective intervention in the management of cLBP patients ${ }^{3}$. Clinical guidelines presented that PA is an integral component of pain rehabilitation services in physiotherapy exercise that is aimed a helping a patient recover from health difficulties ${ }^{4}$. Although PA education have been shown to benefit cLBP patients. Physical inactivity is one of the most crucial factors in worldwide 5 .

Theory of Reasoned Action (TRA) is one of theory for prediction a significant amount of variance for intentions, investigates that individuals health behaviors are decided by their attitudes toward the behaviors and other its' constructs ${ }^{6}$. This theory claims that individuals consider the implications of their actions before deciding to engage or disengage in any given behavior. They confirm the role of thoughts in decision making about engaging in behaviors ${ }^{7}$.

The individuals who have positive beliefs and evaluation regarding outcomes of PA behavior are much more likely to do healthy behavior ${ }^{8}$. this theory check that healthy behaviors will be predicted by the subjective norm ${ }^{9}$.

However, before designing the programs based on TRA, the efficacy of this theory on 
PA Behavior and predicted effective factors should be observed ${ }^{8}$. evidence showed that patients' perceptions of the social cognition and social environment effected on $\mathrm{PA}^{10}$.

Social cognitive concept (SCT) proposed that patients' behavior occurred even as each individual-level cognitive factors interacted with the environmental factors ${ }^{11}$.

In this regard, the present study aimed at the predictors of physical activity behavior among CLBP patients referred to comprehensive health service centers in the Shahid Beheshti University of Medical Sciences (SBUMS) in Tehran, Iran.

\section{Materials and methods}

\section{Gemini Study and participants:}

This study was done among the patients who referred to comprehensive health service centers in the three health networks of North, East and Shemiranat area of Tehran and were affiliated to Shahid Beheshti University of Medical Sciences (SBUMS) in Tehran, Iran, from 13 January to 11 March 2019. All ethical subjects were considered. After describing the aims and methods, all patients were satisfied to be studied and voluntarily signed the written consent form. Research Ethics Committee of Tarbiat Modares University approved the study on July 2019 with ID: IR.TMU.REC.1398.581 and Trial Identification Number in Thai Clinical Trials Registry was TCTR20190728001.

In the present study 400 patients with CLBP who were visited by the physician 280 eligible patients with cLBP eligible for the study were randomly selected. Figure 1 shows the procedure of patients sampling. Inclusion criteria were as have at least reading / 
writing ability in Persian language /Patients with chronic low back pain for at least 12 weeks/ having mental health. Excluding criteria were as Patients who are mentally retarded/ patients with acute or proprioceptive low back pain/ patients with a history of surgery, fracture and inflammation in their spine/ patients suffering from congenital tumors or congenital anomalies, rheumatoid diseases and constriction history in the spine/ Psychological Problems/ Pregnancy/ Infection/ Depression. To identification the predictors of PA behavior(Figure 2), all the Theory of Reasoned Action (TRA) constructs were examined as risk factors to see if they influence on the probability of PA behavior occurrence and were interpreted through odds ratio (OR). SPSS version 21 was used to analyze the data. The odds ratio was used to determine whether particular exposures like TRA constructs could be risk factors for occurrence of the outcome like PA ${ }^{14}$. The sample size was calculated based on following formula (Figure 3) with the parameter from previous document that has been conducted in Iran, were used.

\section{Study Design}

In this cross section study, the demographic questionnaire, questionnaires based on TRA regarding PA behaviors were used. TRA constructs questionnaire consist of 8 subscales according to TRA constructs (Figure 2). The PA behavior questionnaire was discerned using a 14-item questionnaire. Sufficient PA behaviors were defined as 3 times per week more than half an hour.

Qualitative and quantitative approaches were applied by 15 patients with CLBP to assess facial validity of TRA constructs questionnaire through which all their recommendations were inserted into the questionnaire. To confirm the content validity of the questionnaire, the expert panel including 12 experts in different fields of health 
education, health psychologist, psychometric, physical medicine, and pain experts checked all the survey items by which The CVI value of $\geq 0.79$ was observed acceptable for each item. The reliability was determined through Cranach's alpha coefficient that was in acceptable range of 0.70 to 0.88 in 8 subscales according to TRA constructs. Cranach's alpha was obtained as 0.78 . The study questionnaire questions with 7-point scale according to Heidari's study ${ }^{12}$.

\section{Statistical analyses}

To determine the relationship between different TRA constructs with each other and with PA behavior, R Spearman was apply because K-S test displayed the data were non parametric. To predict the factors influencing PA behaviors logistic regression analysis was applied. Lower odds of PA $(P<0.05)$ was considered statistically significant.

\section{Results}

\section{Socio-Demographic Variables}

Totally 400 patients with CLBP recruited of which 280 persons who were visited by the physician and they had inclusion criteria of the study, took part in the study and filled the questionnaires. The means age of the patients was 57.7 years $(S D=13.09)$ and most of them were between 40 and 49 years old (33.2\%). Overall, $38.2 \%$ of the patients with CLBP $(\mathrm{N}=145)$ were housewives. Table 1 show all socio demographic data as well as the Mean (SD) of all studied variables based on TRA.

Logistics' correlation tests were used to evaluate the relevance between the constructs of TRA with each other and with PA behavior. Table 2 shows these correlations. As this 
table shows, there were a direct significant correlation between behavior beliefs and attitude with intention. So that the patients who normative beliefs were more likely to the predictor for subjective norms significantly ( $p$-value $<0.001)$.

As Table 3 shows, this study showed that intention was significant predictor for perform the PA behavior OR (\%95Cl): 1.431(1.148-1.714), p-value <0.001), behavior beliefs could predictor for attitude OR $(\% 95 \mathrm{Cl})$ : $1.276(1.112-1.427)$, $p$-value $=<0.001)$. attitude, normative beliefs, subjective norm and evaluation outcome behavior could predictors the CLBP patients for intention to perform the PA behavior OR (\%95Cl): 1.189(1.033-1.367), p-value=0.016)., OR (\%95Cl): 1.158(1.08-2.208), p-value<0.001) ., OR (\%95Cl):1.104(1.08-1.128), p-value=0.003) ., OR (\%95Cl): $0.814(0.74-1.554), p$-value $<0.001)$, but motivation to comply could predict the cLBP patients for subjective norm OR (\%95CI): 1.077(0.891-1.263), p-value=0.093).

\section{Discussion}

To better understand why adult individuals do not engage in PA is currently guaranteed for researchers and professionals ${ }^{13}$.This study was carried out to address this challenge through predicting factors of PA behavior among Iranian patients with cLBP Referring to Comprehensive Health Service Centers of SBUMS. According to the results of this study, Subjective norm was the most important predictors of PA behavior among patients with cLBP. Subjective norm refers to one's belief that most of the significant others in one's life think one should or should not perform the PA behavior ${ }^{7}$.On the other hand, Attitude means the overall feeling of like or dislike toward any given PA behavior?

The results of this study are in the line of results protected from previous study ${ }^{12}$ as well as the role of subjective norm and attitude were determined as influencing factors for PA behavior. Furthermore, the results of the present study are completely in the line of 
theoretical assumptions of the theory of reasoned action ${ }^{14}$. In Carvalho's study, people who did not have a good attitude toward physical activity prevented their physical activity ${ }^{15}$. Moreover, in accordance with the present study, numerous studies have revealed that subjective norm has been as the best predictor variable for actual PA ${ }^{16-17}$. Therefore, strategies for raising subjective norm, such as strengthening subjective norm through Role Playing and focus groups discussion could lead to more effective health promotion programs for Iranian cLBP patients and should be considered in future intervention ${ }^{18}$. Motivation to comply was as the predictor variable for subjective norm but hidari study Motivation to comply was as the predictor variable for actual intention ${ }^{12}$.

Normative beliefs means How a person thinks that other people beliefs who are significant in his or her life would like him or her to behave ${ }^{7}$ and Motivation Degree means to which a person wants to act to comply in accordance with the perceived wishes of those significant in his or her life ${ }^{7}$. These programs could propose that highly individuals has normative beliefs and evaluation outcome behavior exert greater efforts to master PA behaviors and persist longer in the face of obstacles to such the intention of doing PA behavior and PA behavior. Alison in their study showed that normative beliefs are predictors of persistence of physical activity ${ }^{19}$. Thus, studies have shown that positive social life is a good predictor of $\mathrm{PA}^{20}$.

Behavioral Beliefs means that performing a given PA behavior beliefs leads to certain outcomes $^{7}$. Behavioral beliefs with higher human self-concept are more engaged in $\mathrm{PA}^{21}$. Furthermore, in the present study, it was verified that the patients' behavior beliefs could be a predictor of patients' towards PA likes Kirks study22. Ajzen noted that behavior beliefs Increase the chance of PA involvement ${ }^{23}$. 
This finding is supported by many preceding researches which found that individuals who more patients' beliefs about PA and they're self- evaluation regarding the outcome of PA to the performance of PA are more likely to do this behavior ${ }^{24-25}$.

Outcome evaluations means Value a person places on each outcome resulting from performance of the PA behavior ${ }^{7}$. Outcome evaluation emphasizes that; encouraging patients with CLBP to do preventive behaviors of chronic low back pain, it is better to highlight the benefits and positive outcomes of doing preventive PA behaviors to improve chronic low back pain. Previous evidence verified that preventive behaviors of chronic low back pain behavior could influence CLBP improvement ${ }^{26}$.

This study showed that the patients who were positive beliefs and evaluation regarding outcomes of PA behavior were more like to perform this behavior. Therefore, Cognitive, behavioral, and psychological factors can contribute to the experience of pain among patients with CLBP. One of the psychotherapy interventions is cognitive-behavioral therapy (CBT), which is an effective treatment for chronic general pain, especially low back pain ${ }^{27}$. Cognitive-behavioral interventions are very useful in modifying health beliefs and behaviors as well as eliminating risk factors ${ }^{28}$. Consequently, there is a need for cognitive-behavioral educational intervention based on the theory of reasoned action on changing the beliefs and preventive behaviors of chronic low back pain.

Behavioral intention means the thought to perform the behavior, which is an immediate decide and determinant of the given PA behavior ${ }^{7}$. But behavioral intentions are interpreted as a key predictor of action in several health behavior theories ${ }^{29}$. Somehow health-related intentions could inhibit habits. Consistent this study prediction, the Carroll study showed a significant and positive correlated between the health behavioral 
intentions of CLBP patients with low back pain prevention behaviors ${ }^{30}$. So the final structure of the above theory is Behavior. Behavior means Single, observable action performed by an CLBP patient, or a class and category of actions with a characteristic of a target, action, context, and time (TACO) ${ }^{7}$.

\section{Limitations}

In this study, there are several limitations. First, the data used were collected through self-report that might interfere this study results. The CLBP patients were randomly selected from one university. However a number of key factors like large sample size and the diversity of the subgroups were considered to ensure the representation of the population under study but precaution should be applied if the results of this study could be extended to other patients with CLBP who work in other locations. Psychological tests for the studied cLBP patients were not done. So, it is proposed to consider this evaluation in future studies to see if there would be some correlations with the prediction of the PA behavior. Despite the above limitations, this study has the potent points to display the factors that could influence on PA among patients with cLBP in Iran.

\section{Conclusions}

Findings of this study revealed that normative beliefs and evaluation regarding PA behavior could effect on the intention to engage in greater PA than those with another constructs. Therefore, it is proposed latter studies should be done to confirm these findings and consequently, proper interventions based on these predictors be designed for the patients with CLBP to do more PA behavior. Attitude by the patients with cLBP 
may promotion those from engaging in PA intention while being their behavior beliefs cause in the attitude of doing PA behavior.

\section{Acknowledgement}

The authors would like to thank all the patients who took part in the study. The authors also thank research deputy of Iran National Science Foundation (INSF) and Tarbiat Modares University for its financial support for this study.

\section{Author contribution}

M H D conducted whole study and had full access to all data for analysis. $A H$, supervised the study and also she was involved in drafting the article

FP verified the data analysis. All authors confirmed the final version of the manuscript.

\section{Finance/Disclosure}

None declared.

\section{Conflict of Interest}

"The authors acclaimed that they have no rivaling interests".

\section{References}

1. Brooks, J.M., et al. Relationships between self-determination theory and theory of planned behavior applied to physical activity and exercise behavior in chronic pain. Psychology, health \& medicine. 22, 814-822 (2017).

2. Gardner, T., et al. Combined education and patient-led goal setting intervention reduced chronic low back pain disability and intensity at 12 months: a randomised controlled trial. $\mathrm{Br} J$ Sports Med. bjsports-2018-100080 (2019).

3. Gao, C., et al. Relative effectiveness of different forms of exercises for treatment of chronic low back pain: protocol for a systematic review incorporating Bayesian network meta-analysis. BMJ open. 9, e025971 (2019).

4. Dayer, C.F., et al. Differences in the miRNA signatures of chronic musculoskeletal pain patients from neuropathic or nociceptive origins. PloS one. 14, e0219311 (2019). 
5. Sequin, E., Joseph, J. \& Cowen, V.S. A Review of the Addition of Cognitive Behavioral Therapy to Physical Rehabilitation for Chronic Nonspecific Low Back Pain. JBJS Journal of Orthopaedics for Physician Assistants. 7, e1 (2019).

6. Abraham, C. \& Sheeran, P. Implications of goal theories for the theories of reasoned action and planned behavior. In Planned Behavior 101-122 (Routledge, 2017).

7. Sharma, M. Theoretical foundations of health education and health promotion (Jones \& Bartlett Publishers, 2016).

8. Montano, D.E. \& Kasprzyk, D. Theory of reasoned action, theory of planned behavior, and the integrated behavioral model. Health behavior: Theory, research and practice. 70, 231 (2015).

9. Kautonen, T., van Gelderen, M. \& Fink, M. Robustness of the theory of planned behavior in predicting entrepreneurial intentions and actions. Entrepreneurship Theory and Practice. 39, 655674 (2015).

10. Bosch, S.J. \& Lorusso, L.N. Promoting patient and family engagement through healthcare facility design: A systematic literature review. Journal of Environmental Psychology. (2019).

11. Hoke, A.M., Francis, E.B., Lehman, E.B., Hwang, G.W. \& Kraschnewski, J.L. Training teachers to implement physical activity: Applying social cognitive theory. (2019).

12. Heidari, G. \& Tavafian, S.S. A Theory Based Study Predicting Factors of Physical Activity Behavior among Chronic Low Back Pain Patients Referred to Pain Clinic in Yazd, Iran. International Journal of Musculoskeletal Pain Prevention. 2, 339-345 (2017).

13. McEachan, R.R.C., Conner, M., Taylor, N.J. \& Lawton, R.J. Prospective prediction of healthrelated behaviours with the theory of planned behaviour: A meta-analysis. Health Psychology Review. 5, 97-144 (2011).

14. Ajzen, I. The theory of planned behaviour: reactions and reflections. 2011.

15. Carvalho, F.A., et al. Fear of movement is not associated with objective and subjective physical activity levels in chronic nonspecific low back pain. Archives of physical medicine and rehabilitation. 98, 96-104 (2017).

16. Kim, J., Eys, M., Robertson-Wilson, J., Dunn, E. \& Rellinger, K. Subjective norms matter for physical activity intentions more than previously thought: Reconsidering measurement and analytical approaches. Psychology of Sport and Exercise. 43, 359-367 (2019).

17. Úbeda-Colomer, J., Ginis, K.A.M., Monforte, J., Pérez-Samaniego, V. \& Devís-Devís, J. Predicting physical activity in university students with disabilities: the role of social ecological barriers in the Theory of Planned Behaviour. Disability and Health Journal. (2019).

18. Wyer Jr, R.S. Cognitive organization and change: An information-processing approach (Psychology Press, 2019).

19. Sweeney, A.M., Wilson, D.K. \& Van Horn, M.L. Longitudinal relationships between selfconcept for physical activity and neighborhood social life as predictors of physical activity among older African American adults. International Journal of Behavioral Nutrition and Physical Activity. 14, 67 (2017).

20. Frey, A.-L., Frank, M. \& McCabe, C. Social Reinforcement Learning as a Predictor of Real-Life Experiences in Individuals with High and Low Depressive Symptomatology. (2019).

21. Garn, A.C., et al. Reciprocal effects model of Children's physical activity, physical self-concept, and enjoyment. Psychology of Sport and Exercise. 101568 (2019).

22. Kirk, T.N. \& Haegele, J.A. Theory of Planned Behavior in Research Examining Physical Activity Factors Among Individuals With Disabilities: A Review. Adapted Physical Activity Quarterly. 36, 164-182 (2019).

23. Ajzen, I. The theory of planned behavior. Organizational behavior and human decision processes. 50, 179-211 (1991).

24. Benyamini, Y. \& Leventhal, H. 24 Beliefs and Perceptions of Health and Illness. Cambridge Handbook of Psychology, Health and Medicine. 106 (2019). 
25. Lang, C., et al. Adolescents' personal beliefs about sufficient physical activity are more closely related to sleep and psychological functioning than self-reported physical activity: A prospective study. Journal of sport and health science. 8, 280-288 (2019).

26. Hein, V., Koka, A., Tilga, H., Kalajas, H. \& Raudsepp, L. HOW OBJECTIVELY MEASURED PHYSICAL ACTIVITY IS RELATED TO PSYCHOLOGICAL CONSTRUCTS: A PILOT STUDY AMONG ESTONIAN STUDENTS. LASE JOURNAL OF SPORT SCIENCE is a Scientific Journal published two times per year in Sport Science LASE Journal for sport scientists and sport experts/specialists. 28.

27. Gromisch, E.S., et al. Cognitive behavioral therapy for the management of multiple sclerosisrelated pain: a randomized clinical trial. International Journal of MS Care. (2019).

28. Rahimian Boogar, I. \& Tabatabaeian, M. Effect of cognitive-behavioral group therapy on depression of the patients with chronic low back pain: A 4-months follow up. Koomesh. 13, 209217 (2012).

29. Sheeran, P. \& Conner, M. Degree of reasoned action predicts. (2019).

30. Carroll, L. \& Whyte, A. Predicting chronic back pain sufferers' intention to exercise. 2003. 
Table1. Socio-demographic characteristics of the studied the Patients

\begin{tabular}{|c|c|c|c|}
\hline $\begin{array}{c}\text { Studied variables and } \\
\text { Constructs }\end{array}$ & Sufficient & $\mathbf{N}(\%)$ & Mean (SD) \\
\hline Age & $\begin{array}{c}30-39 \\
40-49 \\
50-59 \\
60-69 \\
70-79 \\
80 \text { and above }\end{array}$ & $\begin{array}{c}40(10.5) \\
126(33.2) \\
112(29.5) \\
59(15.5) \\
32(8.4) \\
11(2.9)\end{array}$ & $57.07 \pm 13.09$ \\
\hline Years of education & $\begin{array}{c}12 \text { years } \\
14 \text { years } \\
\text { 16years(Bachelor) } \\
18 \text { years(Master) }\end{array}$ & $\begin{array}{c}70(18.4) \\
125(32.9) \\
136(35.8) \\
49(12.9)\end{array}$ & $12.08 \pm 10.87$ \\
\hline Marital status & $\begin{array}{l}\text { Single } \\
\text { Married } \\
\text { Widow } \\
\text { Divorced }\end{array}$ & $\begin{array}{l}90(23.7) \\
247(65) \\
25(6.6) \\
18(4.7)\end{array}$ & - \\
\hline occupation & $\begin{array}{c}\text { Housewife } \\
\text { Manager } \\
\text { Employed } \\
\text { Non-employed } \\
\text { Farmer } \\
\text { Worker } \\
\text { Retired } \\
\text { Others }\end{array}$ & $\begin{array}{c}145(38.2) \\
9(2.4) \\
64(16.9) \\
68(17.8) \\
18(4.7) \\
43(11.3) \\
11(2.9) \\
22(5.8)\end{array}$ & - \\
\hline \multicolumn{3}{|c|}{ Intention } & $7.80 \pm 1.18$ \\
\hline \multicolumn{3}{|c|}{ Attitude } & $32.62 \pm 10.22$ \\
\hline \multicolumn{3}{|c|}{ Behavior beliefs } & $10.38 \pm 2.42$ \\
\hline \multicolumn{3}{|c|}{ Evaluation outcome behavior } & $8.26 \pm 2.46$ \\
\hline \multicolumn{3}{|c|}{ Normative beliefs } & $10.39 \pm 2.87$ \\
\hline \multirow{2}{*}{\multicolumn{3}{|c|}{$\begin{array}{c}\text { Motivation to comply } \\
\text { Subjective norms }\end{array}$}} & $12.34 \pm 12.84$ \\
\hline & & & $36.02 \pm 8.12$ \\
\hline
\end{tabular}

Mean (SD): Mean (Standard Deviation) 
Table 2. Correlation matrix of the constructs of Theory of Reasoned Action in Physical Activity in the Patients Referring.

\begin{tabular}{|c|c|c|c|c|c|c|c|}
\hline Variables & 1 & 2 & 3 & 4 & 5 & 6 & 7 \\
\hline 1.Intention & 1.000 & & & & & & \\
\hline 2.Attitude & $r=0.728^{* *}$ & 1.000 & & & & & \\
\hline 3.Behavior beliefs & $r=0.718^{* *}$ & $r=0.635^{* *}$ & 1.000 & & & & \\
\hline 4.Evaluation outcome behavior & $r=0.486^{* *}$ & $r=0.696^{* *}$ & $r=0.057$ & 1.000 & & & \\
\hline 5.Subjective norms & $r=0.413^{*}$ & $r=0.024^{* *}$ & $r=0.013^{* *}$ & $r=0.112^{*}$ & 1.000 & & \\
\hline 6.Normative beliefs & $r=0.566^{* *}$ & $r=0.021$ & $r=0.082$ & $r=0.053$ & $r=0.714^{* *}$ & 1.000 & \\
\hline 7.Motivation to comply & $r=0.212^{*}$ & $r=0.011$ & $r=0.133^{*}$ & $r=0.062$ & $r=0.514^{* *}$ & $r=0.554$ & 1.000 \\
\hline
\end{tabular}

Spearman's ${ }^{* *}$ Correlation is meaningful at 0.01 levels (2-sided).

${ }^{*}$ Correlation is meaningful at the 0.05 level (2-sided).

Table 3. Predictors of Physical Activity behavior based on Theory of Reasoned Action through logistic regression analysis.

\begin{tabular}{|c|c|c|c|c|c|}
\hline $\begin{array}{c}\text { Independent } \\
\text { variable }\end{array}$ & $\begin{array}{c}\text { Variables } \\
\text { predictors }\end{array}$ & B & S.E & P & OR(\%95CI) \\
\hline Intention & behavior & 0.358 & 0.044 & $<0.001$ & $1.431(1.148-1.714)$ \\
\hline Attitude & Intention & 0.173 & 0.072 & 0.016 & $1.189(1.033-1.367)$ \\
\hline Behavior beliefs & Attitude & 0.244 & 0.058 & $<0.001$ & $1.276(1.112-1.427)$ \\
\hline Motivation to comply & Subjective norms & 0.74 & 0.044 & 0.093 & $1.077(0.891-1.263)$ \\
\hline Normative beliefs & Intention & 0.146 & 0.078 & 0.062 & $1.158(1.08-2.208)$ \\
\hline Evaluation outcome behavior & Intention & -0.206 & 0.076 & 0.007 & $0.814(0.74-1.554)$ \\
\hline Subjective norms & Intention & 0.099 & 0.046 & 0.003 & $1.104(1.08-1.128)$ \\
\hline
\end{tabular}


Fig.1. Flow diagram of participation sampling among the Patients Referring to Comprehensive Health Service Centers of Tehran, Iran.

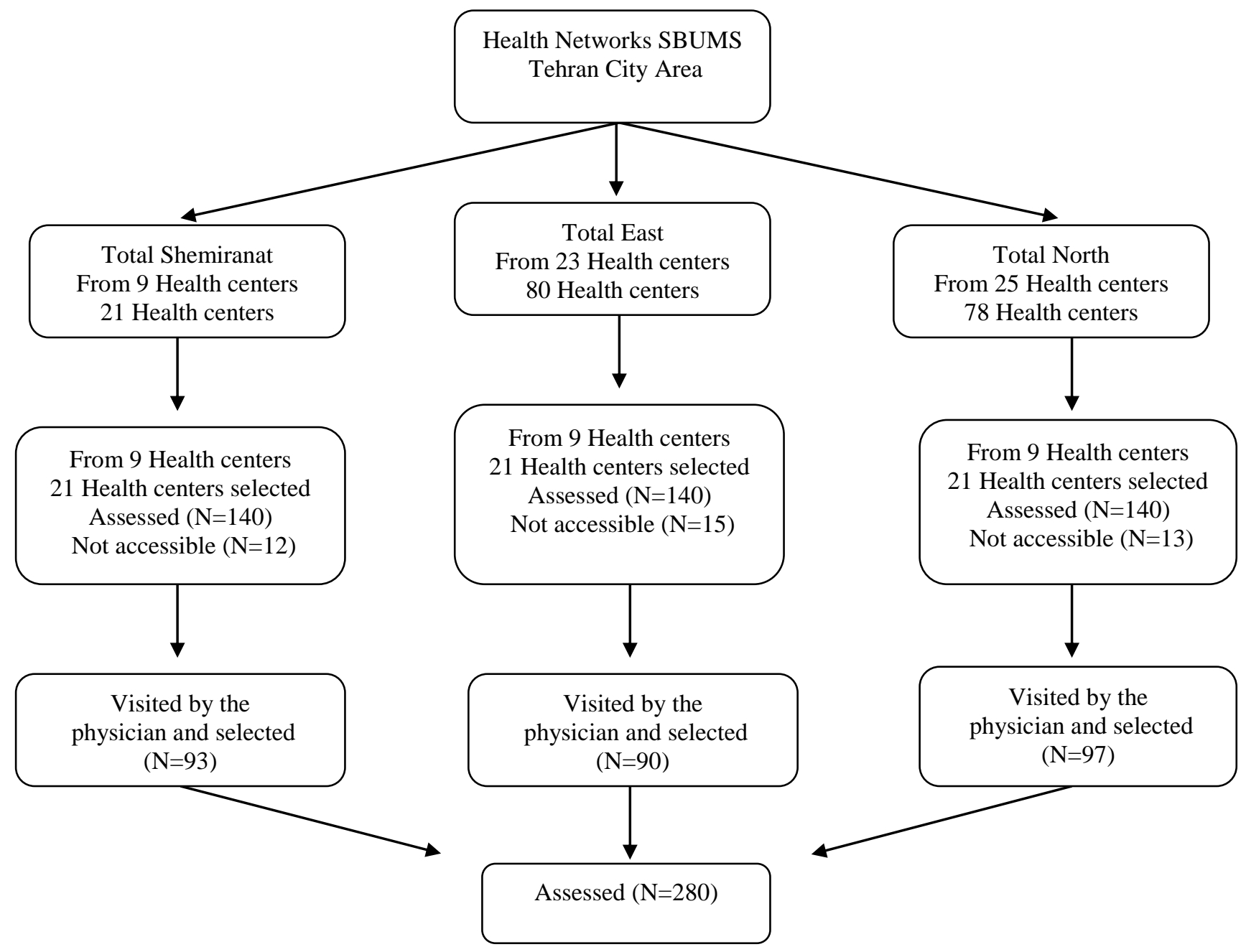


Fig.2. Schematic representation of Theory of Reasoned Action (Ajzen, 2015).

The TRA framework is based on the Theory of Reasoned Action (TRA) by which health behavior predicting factors have been shown.

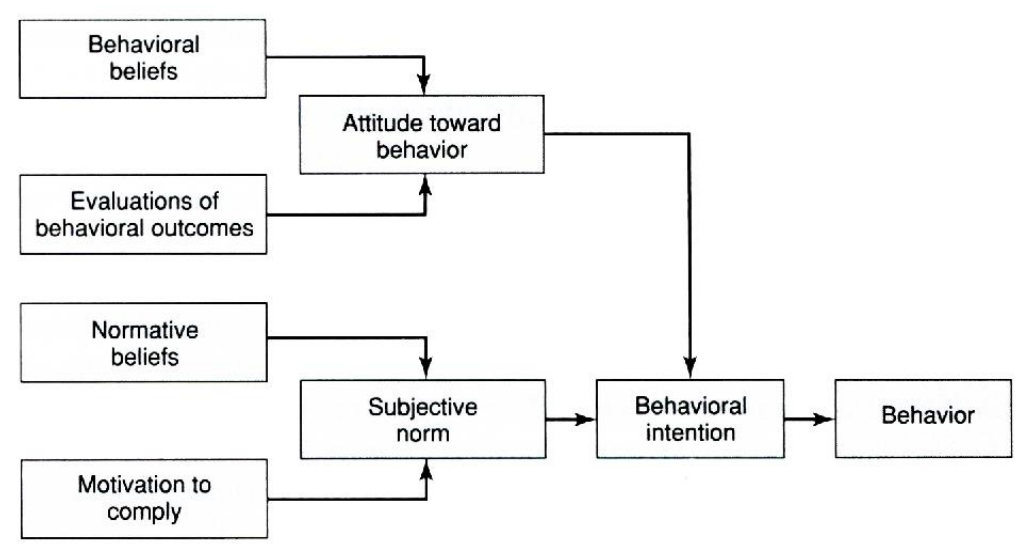


Fig. 3. Sample size formula
$\mathrm{n}=\left(\mathrm{Z}_{\left.1-\alpha^{2} / 2 \cdot \mathrm{p} . \mathrm{q}\right) / \mathrm{d}^{2}} \quad n=\frac{z_{\left(1-\frac{\alpha}{2}\right)}^{2} P(1-P)}{d^{2}}\right.$ $\mathrm{d}=0.05 / \alpha=0.05$

$\mathrm{n}=382 / \mathrm{q}=0.53 / \mathrm{p}=0.47$ 